\title{
IMPROVING THE STAFF DEVELOPMENT INSTITUTIONS UNDER DIGITAL ECONOMY CONDITIONS
}

\author{
Ekaterina A. Popova ${ }^{1}$, Ekaterina M. Medyakova ${ }^{2}$, Zlataslava S. Martemyanova ${ }^{3}$
}

\begin{abstract}
The ongoing improvement of public structures and relationships increasingly based on modern digital technologies causing exponential growth of data flows puts a focus on digitalization issues. Digitalization as a world trend of modern development forms a new type of economy with relations over the production, processing, storage, transfer, and use of increasing amounts of data becoming dominant. In this regard, we identify an increasing interest in the development of personnel. More and more companies tend to create conditions for continuous training of their employees. At the same time, organizations that have been engaged in staff development for a significant period, increasingly focus on ways to improve the staff efficiency in the context of modernization, leading to the need for a thorough study of staff development tools in digital economy.
\end{abstract}

JEL Classification Numbers: M54, J24; DOI: http://dx.doi.org/10.12955/cbup.v6.1189

Keywords: staff, digital economy, training, development, continuous training and education

\section{Introduction}

Digitalization is an actual global trend we should consider when exploring the prospects and directions of development in spheres of daily life. The program "Digital Economy of the Russian Federation" adopted in 2017, confirms the close attention of top Russian management in this field. In the conditions of modern dynamic and accelerating development of all life activity spheres, the informational space plays an increasing role of a connecting link between basic processes of the economy, politics, and society. The information itself, including a digitized form, is transformed into a public resource on a par with the classical ones. The global course towards digitalization and digital transformation has led to an understanding that the task of transition to a digital society is relevant from both a social, economic, and political point of view (Vorobyov \& Kolbanov, 2017). Undoubtedly, the qualitative modernization of public relations in the era of digitalization has a huge potential for economic development and the development of innovative lines of business and production.

Responding to the challenge of modernity, the personnel development system should be mobile and take into account changes in the labor market as well as update the competencies of the digital economy of workers, both existing and future, in order to become a driver of growth in the direction of increasing the efficiency of the labor market.

\section{The impact of digital economy on staff development}

Digital transformation is subject to both production and social spheres including education. There are not only new digital professions and old analogues disappearing, but suddenly needs for personnel in such quantities that simply do not exist in the labor markets (Kononenko, 2017).

The World Bank expert report in 2017 "The Digital Agenda of the Eurasian Economic Union until 2025: prospects and Recommendations" sums up strategic directions for the development of the EAEU countries futurity. Among them, the basic goal is a qualitative growth in the number of jobs in the digital economy and digital inclusion of the population. Digital dividends in implementing the practical strategy of the Digital Agenda of the EAEU provide for the creation of a new working space and the optimal use of human resources in these new conditions. (Digital agenda of the Eurasian Economic Union until 2025: Prospects and Recommendations, 2018)

According to the Huawei's Global Connectivity Index (GCI) rating, measuring the progress of 50 major countries in the way of digital transformation thanks to information and communication technologies (ICT), ranks Russia as 43rd out of 50 with Russia taking the leading position among the

\footnotetext{
${ }^{1}$ Russian Presidential Academy of National Economy and Public Administration, South-Russian Institute of Management of the Russian Presidential Academy of National Economy and Administration, directorcpk@yandex.ru

${ }^{2}$ Russian Presidential Academy of National Economy and Public Administration, South-Russian Institute of Management of the Russian Presidential Academy of National Economy and Administration, cpkglav@mail.ru

${ }^{3}$ Russian Presidential Academy of National Economy and Public Administration, Department of Political Science and Ethnopolitics, South-Russian Institute Of Management of the Russian Presidential Academy of National Economy and Administration, 3lataslava@mail.ru
} 
countries of the EAEU. However, the entire group of countries under consideration is estimated by the World Bank with respect to those of the transition group that have a decent level of access to the Internet. The development of new technologies in these nations can lead to problems due to underdevelopment of certain "analogous" bases (World Development Report, 2016). Thus, it is necessary to take into account a number of potential risks associated with disregarding digital technologies.

The features of the digital economy are not only the full use of information and centrality of the customer, but also the incredibly fast and extremely efficient implementation of state and business structures.

Therefore, the transformation of the economy into a digital one requires a drastic change in the qualitative composition of human resources. For example, in the digital economy as an independent part of it today is considered the application economy, the key indicator of which is the number of specialists able to develop smartphone applications. The best of these specialists create conditions for migration to key agglomerations to apply their professional skills. However, with the development of digital communications and intellectual mobility, the physical move itself is not necessary. A person could remain in their usual conditions and work entirely on the other side of the globe, receiving remuneration for their work. This is not only about individual people, but also about design or production teams (Chebotarev, 2017). Thus, the projects of complex engineering structures and facilities are implemented in a digital space that physically captures several countries or even continents. In these conditions, practically no longer any diploma of education, but actually confirmed qualification of a particular employee on a specific item is in demand (Lokota et al, 2017). These changes are aimed at reducing the cost of production on the one hand, while the appearance of previously impossible products occurs on the other hand. Although these goals were achieved to a large extent thanks to the use of information and communication technologies, and the latter, working closely with other innovative areas in physics, chemistry, biology, and in many other fields, produce new consumer properties of products and thus create new forms of relationships.

Among the features of a modern digital society, it should be noted that it consists of a large array of constantly changing information, in which it is difficult to identify the most relevant, credible and really necessary, both for specialists in personnel services dealing with personnel development issues and for workers themselves interested in self-development. That, of course, affects the choice of personnel development vectors in each individual organization.

The subprograms of the state program "Digital Economy of the Russian Federation" staffing adopted this year are also oriented towards solving the acute problem of a lack of the required number of specialists with a set of competencies in the field of digital relations (Veduta, 2017). This problem predictably leads to a situation of substantial rejuvenation of such labor resources as well as shifting from the workplaces of experienced, but no longer qualified workers in the required field.

Under the conditions examined, the traditional methods of adaptation and development of personnel also could not give the desired effect (Koshkin, 2017). Thus, mentoring of new employees through practical training in the workplace by a highly qualified and experienced professional in conditions where there is a need to update the competence structure does not facilitate the qualitative transfer of the required experience due to a lack of competence amongst most of the staff in the field of digitalization. The instrumentation of delegation through the transfer of authority from the leader to subordinates for the full coverage of the applied skills, knowledge and skills will be effective only in a limited information array and only among those who already demand a set of skills.

Rotation is recognized as the most optimal, but the most time-consuming tool in the organization of the process. However, it loses its effectiveness due to the inequality of employees of different structural divisions in the required set of competencies. Despite the fact that the massive use of digital technologies becomes mainstream, the basic condition for the effectiveness of the rotation tools will be the ability of each of the participants in the process to work effectively in the digital world in a certain unified volume.

Thus, the authors analyzed the existing traditional tools for personnel management and noted that it is becoming extremely important to develop a coordinated approach to modernize the personnel development institutions in order to ensure that the expected benefits are obtained to meet the 
requirements for performance of production and other functions under digitalization conditions. Therefore, the aim of this work is to consider the potential of newly emerging digital solutions in relation to the needs of employers and personnel management services in the context of the general trend of the formation of the Digital Space of the EAEU 2025.

\section{Staff development under the digitalization conditions}

Modernity is characterized by the emergence of new educational forms of training and staff development based on cybernation of education. Traditional methods of personnel training should be supplemented by qualitatively new ways of personnel development. In the context of continuing education, one of the developing innovative technologies is informal, extracurricular education (Lee \& Hammer, 2011). In a corporate learning environment, informal learning involves going beyond formal programs and is based on exchanging information with colleagues both outside and at the workplace. In the process of interaction, people exchange skills and experience. With regard to technologies for out-of-school education, they allow for the realization of continuing education, raising the level of qualification of employees, and obtaining knowledge and skills in a convenient time and place. The challenge is to balance the required staff development tools, taking into account their increasing involvement in digitalization. It seems that the portfolio of such tools meeting the digital challenges of today should include the gamification of educational content, distance and e-learning, and online lessons such as webinars (Kapp, 2012)

Gamification is based on the principles of instant feedback, when using such a tool the information is appreciably acquired, and the acquired skills are qualitatively fixed (Staalduinen \& Freitas, 2011). Undoubtedly, the passage of a quest by an employee will allow him to quickly and promptly assess his competencies that are available or acquired in the training process. Gamification provides forming a stable system of knowledge and skills in the conditions of maximum involvement of the employee in the process. The downside of this tool is the complexity of technical equipment. The content is more expensive with respect to traditional forms of training (Zichermann \& Linder, 2010).

Networking is a popular tool that allows creation of a wide network of business contacts in the process of experience exchange, training events, covering a rather large number of people who are interested in the proposed ideas, projects, and skills of work. Digitalization leads to the scenario where interpersonal communication migrates to the virtual sphere, creating a number of difficulties for the same professionals. Hence, there are difficulties in personal communication due to a lack of sustainable skill. The reverse side of the process is that virtual communication has its own characteristics, anchors, and manipulation methods that should be recognized and used quickly and efficiently. Networking here is a rational tool that can minimize losses for professional growth and performance of labor functions as well as enable acquiring of new skills and competencies.

When using the tools of distance and e-learning, we note the possibility of more rational time spent on work and training. For all their prospectivity, these tools could not completely replace their personal presence in training activities without loss of information assimilation quality. E-learning involves the use of information and communication technologies that allow staff training at a distance, thus creating the opportunity to organize and allocate time for obtaining new knowledge and skills. This method is most effective for companies with a large number of employees geographically distributed.

On-line lessons and webinars could be implemented in a complex way as part of distance and elearning and can perform independent learning functions. Among the advantages of the tools, we note a high degree of interactivity, involvement in the learning process, and the ability to dip into the material at a convenient time.

Applying the method of the expert group technology and the Rapid FoResight methodology, the following basic trends in the formation of a balanced portfolio of digital tools for the development of human capacity have been identified empirically (Table 1). The imposition of these recommendations on the personnel management matrix will enable the maximum possibilities of the proposed digital solutions for organizations of different levels.

Totally, all the listed tools are well-integrated into the Learning Management System (E-learning), which is part of the modern concept of human resources digitalization (HR-digitalization). In the digital environment, LMS interacts with employees and candidates through mobile applications, social networks, and cloud technologies (Rozhkova, 2017). 


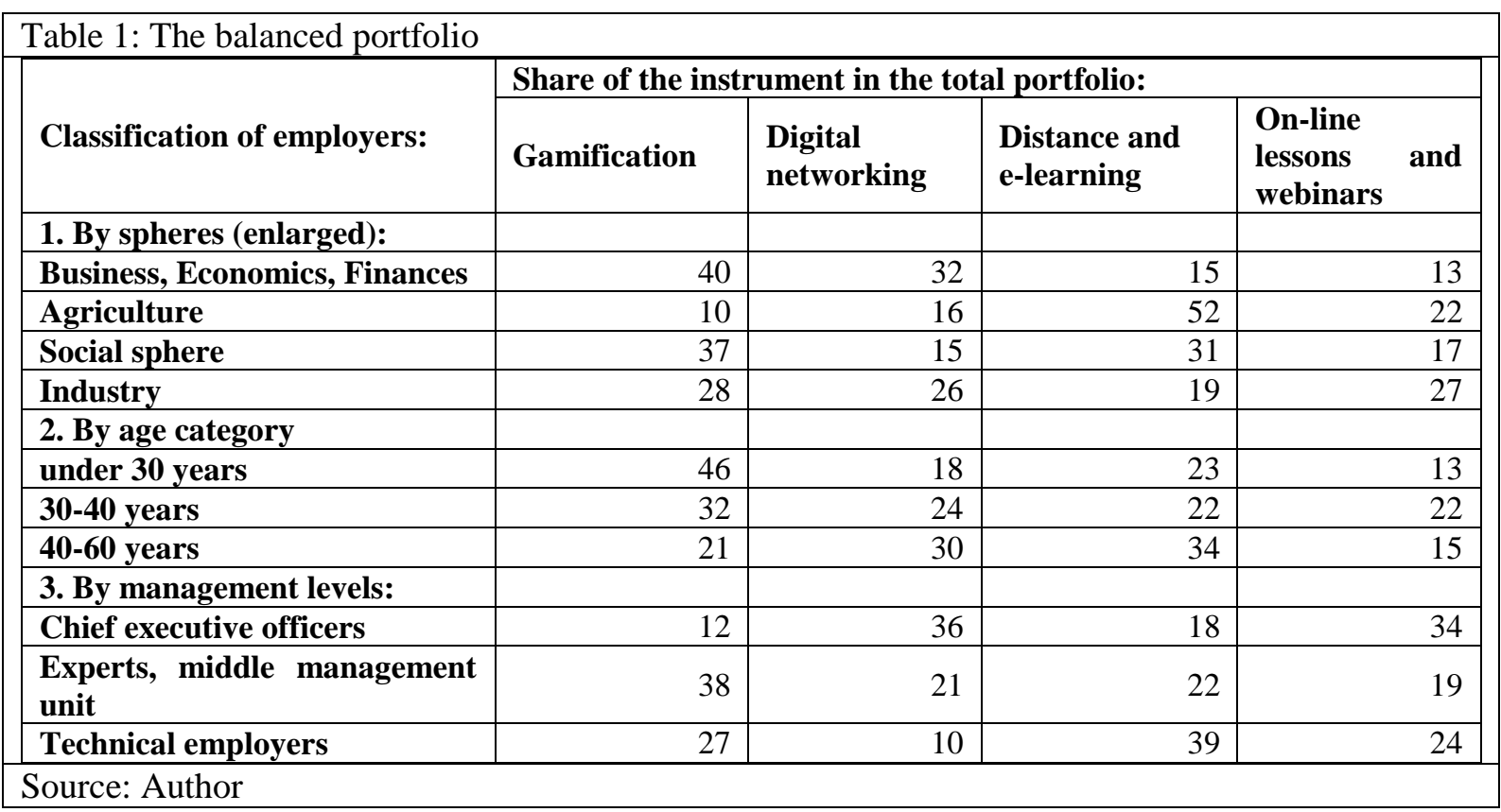

This anticipates a proposal to meet the growing demand for a staff forecasting system connecting the forecasts and needs of key sectors of the economy to the education (retraining) system in conditions of active digitalization based on industry requests.

In addition, it is correlated with those projects of strategic initiatives declared among the proposed solutions of the strategic directions of the development of EAEU countries.

The authors, applying Rapid FoResight methodology, estimate the digital dividends of the application of this portfolio of instruments in the foreseeable future as follows.

The LMS training management system allows reducing the cost of staff training without a decrease in the amount of training, an increase in the competitiveness of the company in the market by means of continuous staff development, and increase of internal and external HR-brand level. It becomes possible to monitor training through statistical tools that enable real-time tracking of users' progress, as well as build global reports on staff training, resulting in a simpler assessment of the effectiveness of learning outcomes. Evaluation of the results of training becomes accurate and less labor-intensive through computer programs processing the information. There is an opportunity to promptly make adjustments to the training programs, taking into account the employee need for them, their personal programs as well as the organization of feedback on the quality of training.

The multiplicative effect of the identified digital dividends can be expressed as follows. At the moment, significant changes are taking place in the labor market thanks to the introduction of new technologies in the systems of knowledge management and career growth. At the same time, economic restructuring has formed a qualitatively different pattern in the practice of personnel management, updating the principles of staff synergy. In the conditions of the new digital information economy, the role of "soft" management technologies is increasing as a factor that provides potential unlimited growth in the effectiveness of human capital management systems through the maximum disclosure of unique personal characteristics, competencies, and the level of education. This type of management technology is characterized by a departure from the functional and administrative model of labor coercion and the transition to the so-called "participation economy" focused on the formation of direct interest of employees in the results of labor and participation in managerial processes.

The multiplicative effect allows, on the one hand, to accelerate the digitization of all management processes and adaptation to digital requirements, while on the other hand to receive dividends as a result of maximizing the effective use of human resources without compromising the economic processes of the organization. The key driver of a successful transition to quality labor resources of the digital age as a whole is to become the sphere of education, which also turns into a digital format. The first step for this can be the training of an updated teaching staff on the basis of the so-called umbrella model involving a cycle of activities from the formation of an proactive active methodological core to 
dissemination by mutual learning by people of each other. A number of authors consider this direction in the context of already existing digital educational platforms such as SDO Moodle (Breslav, 2017). The second stage could include the creation of an accessible unique information portal for human resource services designed to provide the ranking of educational services for business activity with a qualitative answer to the challenges of our time. This information system should contain the criteria for selecting tools that can give a specific set of recommendations for the development of existing personnel, taking into account their digitalization. It seems that this platform will create and adjust the portfolio of tools with consideration to the required set of competencies of the company's staff. Due to this selection, it will be possible to accumulate the optimal portfolio of digital development tools for the customer. Technologies and instruments of portfolio balancing have long and successfully been applied in the sphere of investment decisions and in the sphere of project management. The third step for a competent transformation in the digital economy can be the creation of a demonstration platform for the development and testing of new digital educational tools based on the principles of crowdsourcing and crowdfunding. The system should allow testing and exploring the possibilities of educational tools offered by any users developing their initiatives and developments in the field of personnel development in the era of digitalization.

\section{Conclusion}

The improvement of personnel is one of the priority directions of development in the conditions of modernization and digital economy development. It is important for Russian companies to assess prospects for the application of new management technologies to form an effective strategy for human resources capacity development. If there is a disproportion in knowledge management systems and the development of human capital in companies, the effectiveness of the personnel policy as a whole can be significantly reduced.

The need for highly qualified personnel creates the conditions for:

- training for new directions in the development of technology, economics, and management, enhancing the role of staff development,

- the emergence of a stable set of knowledge and skills, new competencies in the field of digitalization;

- the formation of personnel with digital culture;

- development of digital culture at enterprises, in organizations.

The widespread use of digital solutions for the active inclusion of labor resources within the strategic development directions of the EAEU countries, which will maximize the use of human resources, is of particular importance for obtaining the expected digital dividends.

The ongoing procedure of digitizing the majority of management processes has made it possible to determine the ways of employing human resources as part of a package of digital initiatives.

The application and expansion of the proposed "basic" portfolio of instruments will require initial financial investments, a number of administrative decisions, and structural adjustment of the management of personnel in the EAEU countries. (Breene, 2016)

Given the changes in the globalization vector, namely, the introduction of the digital economy, it is necessary to pay attention to the reconstruction of the education sector. Digital technologies should play a key role in development of staff skills and competencies in the context of a decrease in the role of traditional tools for its development and adequate replacement with a new portfolio of tools discussed before.

\section{References}

Breene K. (2016). The 10 countries best prepared for the new digital economy, WEF

Breslav E.P. (2017) How to develop a digital economy in your organization today. Quality. Innovation. Education. No. 4 (143). Pp. 51-61

Chebotarev S.S. (2017). Technologies of project training and development of video games for the preparation of students of IT directions in conditions of the emergence of the digital economy. Modern Higher School: an Innovative Aspect. Vol. 9. No. 3 (37). Pp. 47-56.

Digital agenda of the Eurasian Economic Union until 2025: Prospects and Recommendations. 2018 World Bank Survey

Fedorkov A.A, Biryukov O.A. (2017). The digital economy: features of management and development tendencies.

Petersburg economic journal. № 3. P. 60-66. 
Izmailova M.A. (2017). The Digital Economy of Russia: Current State and Development Prospects Issues of the Regional Economy. T. 33. № 4. P. 32-38.

Kapp K. M. (2012). The gamification of learning and instruction: game-based methods and strategies for training and education. -John Wiley \& Sons.

Karl. M. Kapp (2012). The gamification of learning and instruction: game-based methods and strategies for training and education. John Wiley \& Sons.

Kononenko A.A. (2017). Global Trends in Human Capital in the Transition to the Digital Economy Synergy of Sciences. T. 1. No. 18. S. 382-385.

Koshkin R.P. (2017). The digital economy is a new stage in the development of the information society in Russia. Strategic priorities. No. 3 (15). Pp. 4-15.

Lee, J. J. \& Hammer, J. (2011). Gamification in Education: What, How, Why Bother? Academic Exchange Quarterly, 15. Lokota O.V., Popova E.A., Zolochevskaya E.Yu., Medyakova E.M., Ermashov H.Yu., Morozova A.I.(2017) Specificity of management in the contract system of the Russian Federation. Publishing house LLC "Altair".

Rozhkova D.Yu. (2017). Digital platform economy: definition and principles of operation Management of economic systems: electronic scientific journal. No. 10 (104). C. 32

Van Staalduinen J. P., de Freitas S. A (2010.) Game-Based Learning Framework: Linking Game Design and Learning//Learning to play: exploring the future of education with video games. -T. 53. -C. 29.

Veda E.N. (2017). The digital economy will lead to an economic cyber system. International life. No. 10. P. 87-102.

Vorobyov A.I, Kolbanov M.O. (2017). Infocommunication and the Digital Economy Alley of Science. T. 1. No. 15. P. 791 799 .

World Development Rreport 2016, p.2

Zichermann G., Linder J. (2010). Game-based marketing: inspire customer loyalty through rewards, challenges, and contests. -John Wiley \& Sons. 